\title{
Variations in population vulnerability to tectonic and landslide-related tsunami hazards in Alaska
}

\author{
Nathan J. Wood · Jeff Peters
}

Received: 10 June 2014/ Accepted: 18 August 2014/Published online: 7 September 2014

(C) The Author(s) 2014. This article is published with open access at Springerlink.com

\begin{abstract}
Effective tsunami risk reduction requires an understanding of how at-risk populations are specifically vulnerable to tsunami threats. Vulnerability assessments primarily have been based on single hazard zones, even though a coastal community may be threatened by multiple tsunami sources that vary locally in terms of inundation extents and wave arrival times. We use the Alaskan coastal communities of Cordova, Kodiak, Seward, Valdez, and Whittier (USA), as a case study to explore population vulnerability to multiple tsunami threats. We use anisotropic pedestrian evacuation models to assess variations in population exposure as a function of travel time out of hazard zones associated with tectonic and landslide-related tsunamis (based on scenarios similar to the $1964 M_{\mathrm{w}} 9.2$ Good Friday earthquake and tsunami disaster). Results demonstrate that there are thousands of residents, employees, and business customers in tsunami hazard zones associated with tectonically generated waves, but that at-risk individuals will likely have sufficient time to evacuate to high ground before waves are estimated to arrive 30-60 min after generation. Tsunami hazard zones associated with submarine landslides initiated by a subduction zone earthquake are smaller and contain fewer people, but many at-risk individuals may not have enough time to evacuate as waves are estimated to arrive in 1-2 min and evacuations may need to occur during earthquake ground shaking. For all hazard zones, employees and customers at businesses far outnumber residents at their homes and evacuation travel times are highest on docks and along waterfronts. Results suggest that population vulnerability studies related to tsunami hazards should recognize non-residential populations and differences in wave arrival times if emergency managers are to develop realistic preparedness and outreach efforts.
\end{abstract}

\footnotetext{
N. J. Wood ( $\square)$

Western Geographic Science Center, U.S. Geological Survey, 2130 SW 5th Avenue, Portland, OR, USA

e-mail: nwood@usgs.gov

J. Peters

Western Geographic Science Center, U.S. Geological Survey, 345 Middlefield Road, Menlo Park, CA, USA

e-mail: jpeters@usgs.gov
} 
Keywords Tsunami $\cdot$ Earthquake $\cdot$ Landslide $\cdot$ Alaska $\cdot$ Vulnerability

\section{Introduction}

A significant element of tsunami risk reduction is educating at-risk populations about the potential for future events, how they should prepare, and what they should do if a tsunami is detected (National Research Council 2011). Although fairly simple in the abstract, preparing at-risk populations for future events in a specific community is challenging for public officials given the potential vulnerability to multiple types of tsunami sources, the inherent uncertainty of where and how large the next event will be, and the high spatial and temporal variability of the population. Developing effective tsunami preparedness strategies requires an understanding of not only the tsunami hazard but also how individuals are vulnerable to the hazard, in terms of their exposure (e.g., magnitude and spatial proximity), sensitivity (e.g., mobility issues, language barriers, or cultural constraints), and adaptive capacity (e.g., awareness, preparedness, and evacuation potential).

To support tsunami preparedness and education efforts, there has been considerable work in recent years to characterize population vulnerability to tsunamis, including exposure assessments (Wood 2007; Lovholt et al. 2012), demographic sensitivity analyses (Wood et al. 2010), pedestrian evacuation modeling (e.g., Jonkmann et al. 2008; Post et al. 2009; Yeh et al. 2009; Wood and Schmidtlein 2012, 2013; Freire et al. 2013), and vertical evacuation siting (Park et al. 2012; Wood et al. 2014). All of these efforts contribute to understanding whether or not at-risk populations would have sufficient time to evacuate hazard zones before tsunami waves arrive and for recognizing what landscape or demographic characteristics may hinder their ability to evacuate. To date, efforts to characterize population vulnerability to tsunamis have focused primarily on residents and on single tsunami hazard zones. Focusing only on residents may be problematic if a coastal community has a significant workforce and tourism component along its waterfront. With regard to tsunami source, hazard and evacuation maps designed for the public typically reflect one zone that characterizes a single, worst-case scenario (e.g., Walsh et al. 2000) or a maximum zone that summarizes multiple sources (e.g., Nicolsky et al. 2011, 2013; Suleimani et al. 2002, 2010; Wilson et al. 2008), although there are exceptions that include distant and local tsunami hazard zones (e.g., Oregon Department of Geology and Mineral Industries 2013).

The decision to only show one hazard or evacuation zone is often rooted in the desire to prepare communities for worst-case tsunami scenarios and to minimize potential confusion in understanding and properly reacting to information about multiple zones (National Research Council 2011). However, the spatial extent of potential inundation in a coastal community and wave arrival times can vary dramatically when comparing distant tsunamis generated thousands of kilometers away, local tsunamis caused by a large-magnitude earthquake, or a local tsunami caused by a landslide or volcanic eruption. The intended response of an at-risk population will also vary depending on the threat, ranging from selfevacuations in a matter of minutes for local sources (earthquakes, landslides, and eruptions) to managed evacuations involving multiple agencies over the course of several hours for a distant tsunami. There also may be tsunami events on the spectrum between these two types, such as waves that are generated by a relatively local earthquake but take more than an hour to arrive due to regional bathymetry and distance from the epicenter. The communication of multiple tsunami threats may be challenging in public outreach but may be 
critical, given the potential implications for community preparedness, evacuation maps developed for the public, and evacuation procedures.

To explore potential issues related to portraying multiple tsunami sources as a single hazard zone, we examine variations in population vulnerability based on multiple tsunami threats in the Alaskan coastal communities of Cordova, Kodiak, Seward, Valdez, and Whittier (Fig. 1). We focus on documenting variability in population exposure as a function of travel time out of hazard zones in these communities based on multiple tsunami scenarios and anisotropic pedestrian evacuation models. We chose these Alaskan communities because of the range in nearby tectonic and landslide-related tsunami sources and varied geography, yet they share the common issue of how to best educate and prepare their at-risk populations for future tsunamis. There is also extensive documentation of tsunami impacts in these communities from the $1964 M_{\mathrm{w}} 9.2$ Good Friday earthquake disaster (e.g., Lemke 1967; Norton and Haas 1970; Rogers 1970; Arno and McKinney 1973; Barry 1995; Lander 1996) and recent efforts to model future tsunami threats (e.g., Nicolsky et al. 2011, 2013; Suleimani et al. 2010, 2002). Our research will help Alaskan officials in their efforts to develop awareness and preparedness strategies that address multiple tsunami threats. This case study also highlights issues of population vulnerability that are likely to be common in other coastal communities throughout the world that are threatened by multiple types of tsunami hazards.

\section{Study area}

The proximity of the seismically active Alaska-Aleutian subduction zone has made Alaskan coastal communities on the northern Pacific Ocean susceptible to past tsunamis generated by local earthquakes, distant earthquakes, landslides, and volcanic eruptions (National Geophysical Data Center/World Data Service 2014). The most significant local tsunami to strike Alaskan coastal communities in recent history was associated with the $M_{\mathrm{w}} 9.2$ Good Friday earthquake that occurred on March 27, 1964, centered in the Prince William Sound region (United States Geological Survey 2012). Earthquake ground shaking lasted approximately 3-4 min (Grantz et al. 1964; Hansen et al. 1966). Tsunami waves were measured throughout the Pacific Ocean basin and ultimately were responsible for 124 deaths and \$119 million in losses (\$USD, 1964 dollars), making it the costliest and second deadliest tsunami event in US history (National Geophysical Data Center/World Data Service 2014).

Two types of tsunamis were generated in Alaska during the $1964 M_{\mathrm{w}} 9.2$ Good Friday earthquake. Regional tsunamis were generated from the initial displacement of the sea floor within the rupture area and waves struck several Alaskan communities within 25-45 min after initial ground shaking, which began at 5:36 p.m. (Alaska Standard Time). The waves continued to strike almost hourly until the next morning (National Geophysical Data Center/World Data Service 2014). Tsunamis were also generated by massive submarine landslides along the waterfront of several coastal communities that were initiated within seconds by the initial earthquake ground shaking (Lemke 1967). These landsliderelated tsunamis were typically confined to the bay in which the landslides occurred, but inundated coastal communities in $<2 \mathrm{~min}$ after initiation by the earthquake ground shaking, suggesting that inundation occurred during the 3-4 min of earthquake ground shaking. Eyewitnesses of the 1964 disaster in Valdez reported that waterfront structures slid into the water within seconds of the first tremor, followed almost immediately by tsunami waves (Coulter and Migliaccio 1966). 


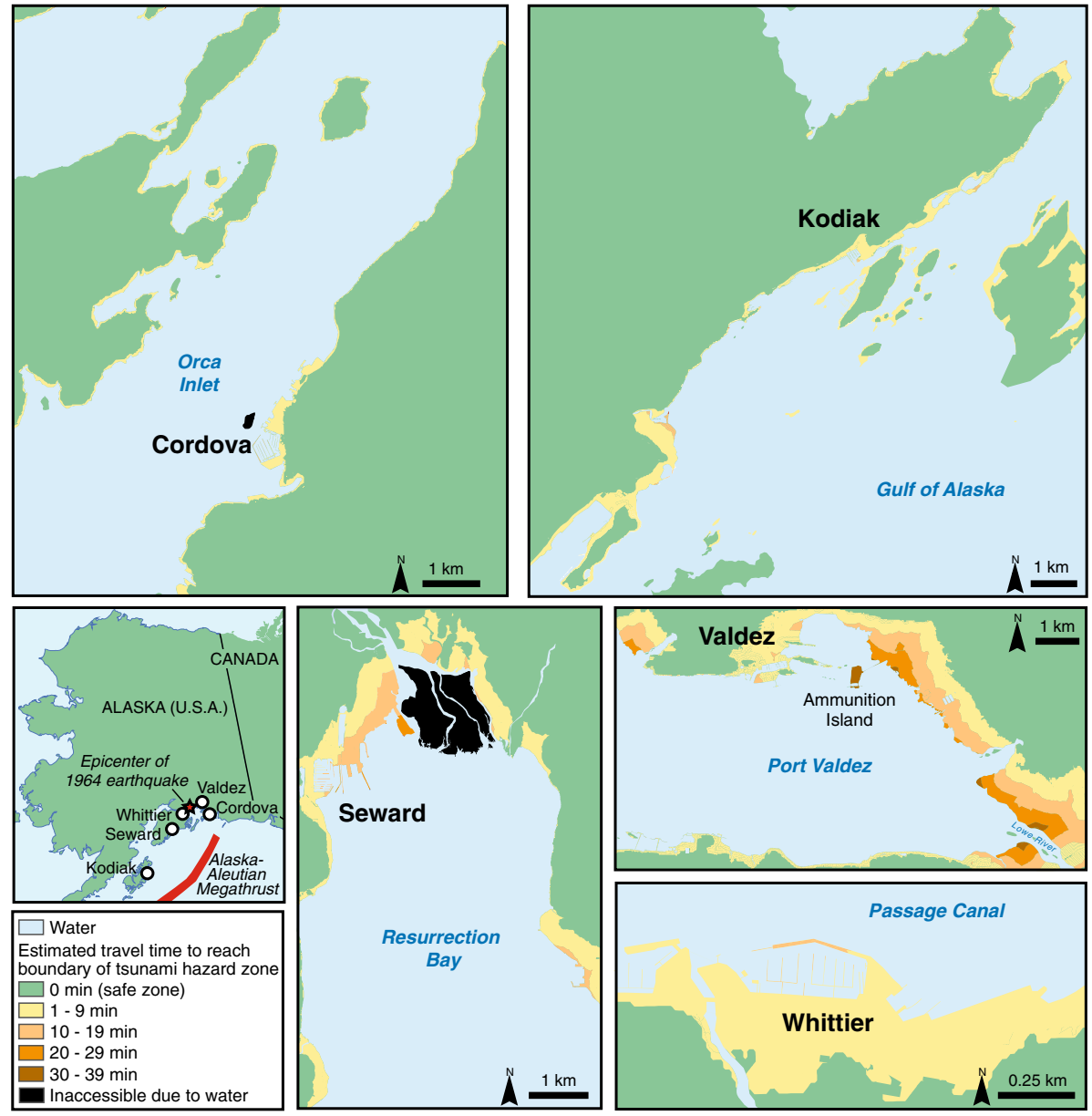

Fig. 1 Regional map showing community locations and maps of modeled pedestrian evacuation travel times in Cordova, Kodiak, Seward, Valdez, and Whittier (Alaska, USA) relative to maximum tsunami hazard zones and assuming a slow walking speed of $1.1 \mathrm{~m} / \mathrm{s}$. Map extents for each community vary considerably and are based on the extent of resident and employee locations within a community

For this study of multiple tsunami threats, we focus on five Alaskan coastal communities (Cordova, Kodiak, Seward, Valdez, and Whittier; Fig. 1) due to recent efforts to model tsunami threats from multiple sources in these areas, as well as the extensive damage they suffered from both earthquake- and landslide-related tsunamis during the 1964 disaster. A full account of damages to these communities has been well documented elsewhere (e.g., Lemke 1967; Norton and Haas 1970; Rogers 1970; Arno and McKinney 1973; Barry 1995; Lander 1996), but the following summarizes tsunami-related impacts during the 1964 disaster.

- Seward Landslide-related waves were the first to strike and were generated when portions of an alluvial fan, which were exposed due to low tide, began to slide into the adjacent bay 30-45 s after the start of the initial ground shaking (Lander 1996; Lemke 1967). Seward impacts included thirteen deaths, 86 houses were completely destroyed, 
269 houses were heavily damaged, and approximately $\$ 22$ million in reconstruction costs as a result of damage from ground shaking and tsunami flooding (Lemke 1967; Suleimani et al. 2010).

- Valdez A tsunami was generated when a massive submarine landslide of approximately 75 million $\mathrm{m}^{3}$ of unconsolidated material slid into the bay. Waves arrived approximately $45 \mathrm{~s}$ after the initial shaking and inundated the waterfront up to two blocks inland, killing 30 people at the city dock (Lander 1996; Nicolsky et al. 2013).

- Cordova Cordova experienced the least amount of damage attributed to seismic activity or tsunami flooding from the 1964 event and had one casualty from drowning due to tsunami flooding at a nearby fishing camp. The first noticeable tsunami wave occurred approximately over an hour after initial ground shaking. No landslide-related tsunami waves were reported during the 1964 event (Nicolsky et al. 2014; Lander 1996).

- Kodiak Tsunami waves associated with the earthquake hit shore approximately $40 \mathrm{~min}$ after the shaking began and destroyed the harbor and many waterfront properties, as well as killing six people; however, landslide-related waves were not reported (Lander 1996; Suleimani et al. 2002).

- Whittier Although the smallest of communities in this study, Whittier suffered the largest proportional loss of life when 13 of its 70 residents in 1964 died due to a landslide-generated tsunami which arrived about $1 \mathrm{~min}$ after the initial shaking was felt. Extensive earthquake and tsunami-related damage destroyed the small boat harbor, stub pier, car-barge slip dock, U.S. Army storage tanks, a lumber camp (where 12 of the 13 fatalities occurred), and damaged the FAA station, airstrip, highway, and railroad bridges spanning Whittier Creek (Lander 1996; Nicolsky et al. 2011).

\section{Methods}

To characterize variations in population vulnerability due to multiple tsunami threats in the various Alaskan coastal communities, we estimated population distributions using various demographic data and modeled pedestrian evacuation potential out of hazard zones. Pedestrian evacuation potential was modeled using an anisotropic, least cost distance (LCD) model implemented in ESRI's ArcMap 10.1/SP1 software, following methods described in greater detail in Wood and Schmidtlein $(2012,2013)$. We chose a LCD approach over an agent-based approach (e.g., Yeh et al. 2009) because we wished to focus on the evacuation landscape, instead of anchoring results to a specific scenario of population magnitudes and locations. This LCD approach focuses on landscape characteristics related to elevation and land cover to calculate the most efficient path from every location in a hazard zone to the boundary of the zone, with the difficulty of traveling through each location represented as a cost surface. Anisotropy incorporates direction of travel (e.g., the influence of a given slope will vary whether travel is uphill, downhill, or perpendicular to the slope). The path distance approach within LCD modeling calculates distances and slopes between cells of varying elevations. The modeling estimates travel times based on optimal routes; therefore, actual travel times may be greater due to evacuee route preferences and environmental conditions during an evacuation.

Data required for the pedestrian evacuation modeling include a hazard zone, elevation, and land cover. Various tsunami hazard zones were used to delineate likely areas of inundation in the five communities (Table 1). To represent tectonically generated wave scenarios in each community, we used the maximum tsunami hazard zone, which reflects 


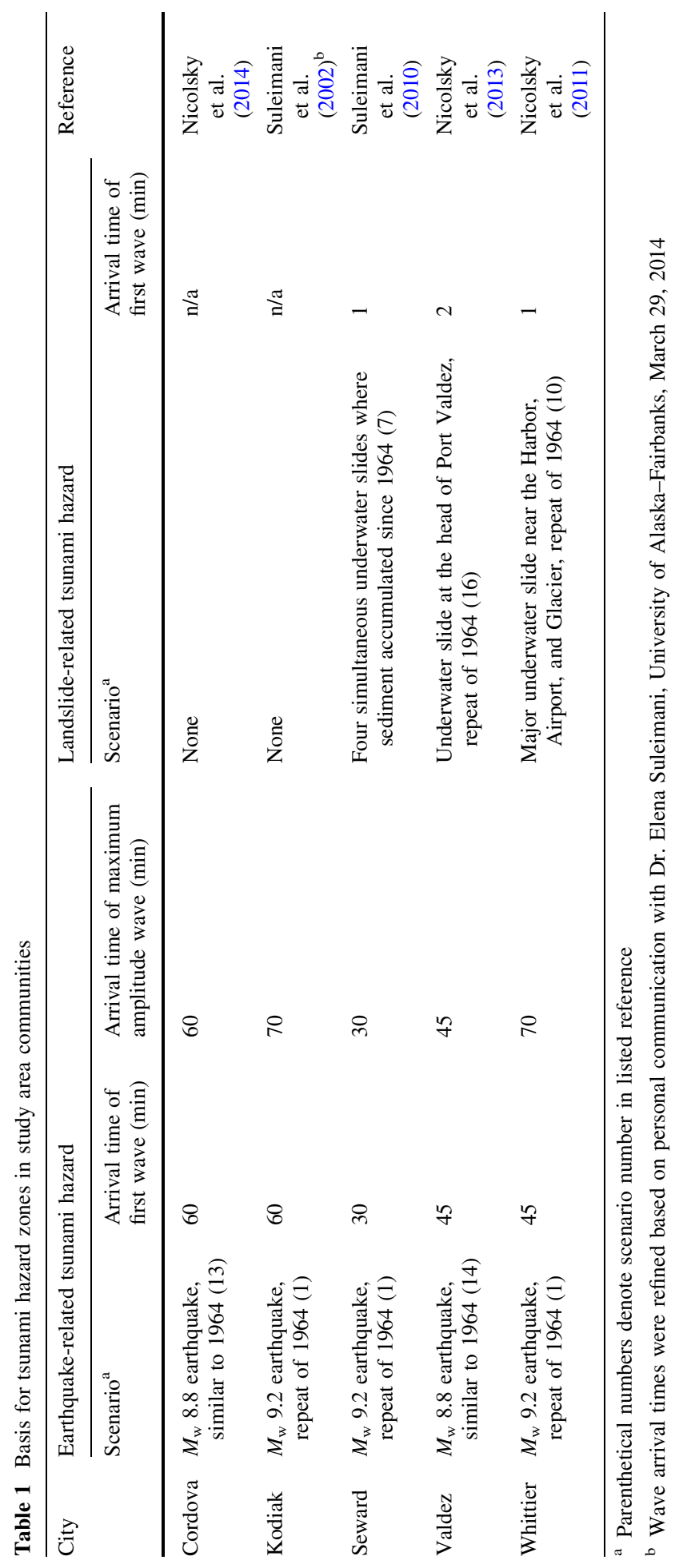


multiple earthquake scenarios similar to the 1964 event in Alaska, instead of a specific tectonic scenario. We did this in order to capture the full extent of potential inundation related to seismic generation since inundation extents from individual scenarios had subtle variations due to inherent uncertainties in seismic source parameters. Tectonic scenarios identified in Table 1 were chosen only to approximate wave arrival times and represent the closest approximation to the maximum tsunami hazard zone in terms of spatial extent. Estimated arrival times for the first waves in the worst-case tectonic tsunami sources that we considered are on the order of 30 (Seward) to $60 \mathrm{~min}$ (Cordova), but actual arrival times will depend on each community's distance from the fault displacement. The first wave may represent the largest wave in some communities (Valdez, Seward, Cordova), but may be followed by larger waves in other communities (Kodiak, Whittier); therefore, complete inundation of the modeled hazard zones may or may not occur with the first wave (Table 1). Because models cannot fully capture all aspects of future events, there is also the possibility of smaller waves that arrive sooner than expected and inundate portions of the hazard zone. Landslide tsunami scenarios have been developed for Seward, Valdez, and Whittier and each represent various landslide scenarios similar to 1964 experiences. Estimated wave arrival times for landslide-related tsunamis are on the order of $1 \mathrm{~min}$ in Seward and Whittier and 2 min in Valdez based on tsunami modeling (Table 1).

Various digital elevation models and imagery (Table 2) were used to develop model input grids of speed conservation values (SCV), which represent the proportion of maximum travel speeds that are expected at a location with given conditions. Digital elevation models were used to derive slope, which was then coupled with a lookup table based on Tobler's (1993) hiking function that converts slope to SCV. Imagery was used to manually classify and map land cover, which was then reclassified into SCV based on terrain-energy coefficients discussed in Soule and Goldman (1972). Values include "No Data" to note where travel is not possible (e.g., over water and through fences or buildings) and then a range from 0.5556 to 1.0 to note the percentage of the base travel speed (assuming constant energy expenditure). SCV were mapped for impervious surfaces (1.0), grass, dirt/gravel surfaces, and other developed areas (0.9091), light brush (0.8333), heavy brush (0.6667), and wetlands, sand, and shoreline (0.5556).

Cost surfaces that integrate land cover and elevation SCV maps were generated using ESRI's Path Distance tool and then converted to maps of pedestrian travel times using a travel speed assumption of a slow walk at $1.1 \mathrm{~m} / \mathrm{s}$ (United States Department of Transportation 2009). A slow walk travel assumption is typically preferred given a mixed population with ranges in age and physical mobility (Wood and Schmidtlein 2012). Because of the slow travel speed assumption and the likelihood that many at-risk populations will move faster, estimates of population exposure as a function of travel time should not be interpreted as definitive estimates of safety or mortality. Waves associated with future events may not arrive exactly as modeled, resulting in different inundation patterns and arrival times, such as smaller waves arriving sooner than modeled results. Additional factors that may increase travel times are environmental conditions at the time of an evacuation (e.g., inclement weather, snow cover, and nighttime) and impacts to evacuation routes due to other seismic hazards (e.g., ground shaking, ground rupture, lateral spread, liquefaction, and rubble of damaged structures from ground shaking). For the landslide-related tsunami hazard zones, we modeled travel times also assuming a slow walking speed of $1.1 \mathrm{~m} / \mathrm{s}$. Eyewitnesses of the 1964 earthquake describe ground shaking strong enough to stop a moving person, rolling landscapes with vertical displacements on the order of $1 \mathrm{~m}$, and people not reacting until the severe ground shaking ended (Coulter and Migliaccio 1966). Therefore, we assume that if individuals do attempt to evacuate 


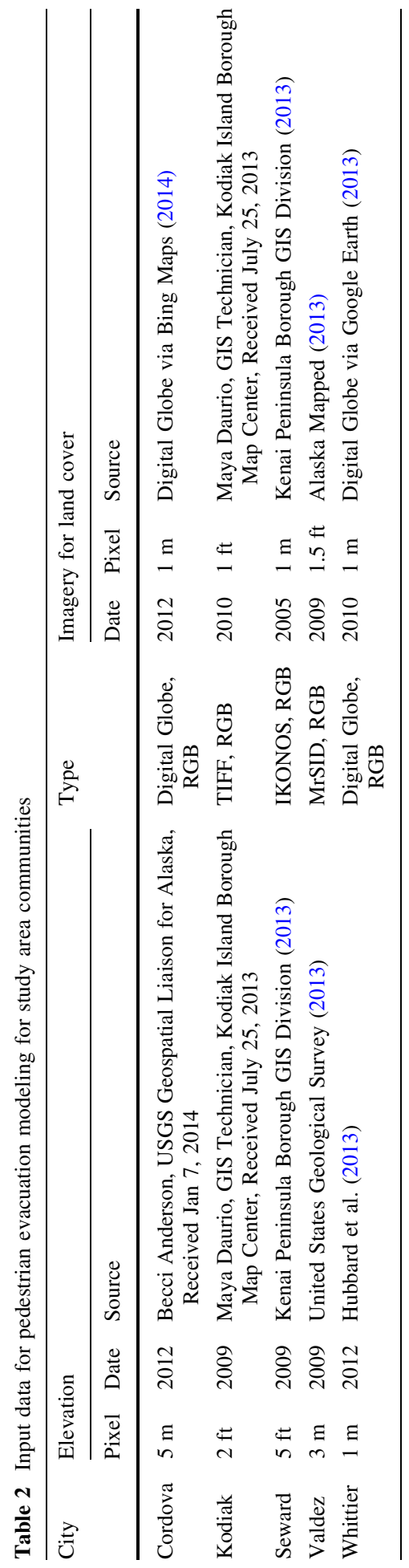


during the ground shaking, then they will be effectively moving at a slow walking speed because of the limitations posed by the landscape.

Various datasets were assembled to characterize the at-risk population. Residential estimates were created by manually identifying residential structures in the imagery and then disaggregating block-level population estimates in the 2010 U.S. Census Bureau count (United States Census Bureau 2012) to residential structures. Employee points were developed using a 2011 version of the Infogroup Employer Database (Infogroup 2011), which is a proprietary database that includes business locations, employee counts, and type based on the North American Industry Classification System (NAICS). We used NAICS codes to classify certain businesses as public venues (e.g., museums, overnight accommodations, and parks or other outdoor venues), dependent-population facilities (e.g., child services, elderly services, medical centers, and K-12 schools), and other community businesses that would likely have substantial numbers of customers (e.g., banks or credit unions, civil or social organizations, gas stations, government offices, grocery stores, libraries, and religious organizations). Each population layer was overlaid on the evacuation time maps to estimate the number of individuals or facilities in terms of travel time to reach a boundary of the tsunami hazard zone. In addition to spatial population data, we searched the internet for insight on additional populations related to waterfront festivals, cruise ships, and other events.

\section{Results}

\subsection{Population exposure to tectonic tsunamis}

There are 2,861 residents and 7,150 employees in the maximum tsunami hazard zones (which reflect tectonic wave scenarios) of the five study area communities (Fig. 2a). The majority of residents in the hazard zone among the communities are in Kodiak (53\%), followed by Valdez (28\%), Seward (12\%), Cordova (5\%), and Whittier (2\%). Kodiak also had the highest percentage of the total employees in the hazard zone among these communities, but to a lesser degree than residents (42\% of the study area employees compared to $53 \%$ of the residents) due to higher percentages of total employees in Cordova (13\% compared to $5 \%$ ) and in Seward (16\% compared to $12 \%$ ).

The number of employees in the hazard zone is substantially larger than the number of residents in the hazard zone for each community (e.g., 2:1 ratio of employees to residents in Kodiak, a 3:1 ratio in Valdez and Seward, and a 6:1 ratio in Cordova), except in Whittier that has relatively equal numbers (51 employees and 59 residents) (Fig. 3). This indicates that in each community (aside from Whittier), substantial numbers of the at-risk population do not live in the tsunami hazard zone but enter it for their jobs. From a hazard awareness and evacuation perspective, these individuals may not be as familiar with their surroundings as those that live in the hazard zone, which could delay their ability to navigate during a tsunami evacuation.

A comparison of the number of residents in the hazard zones to the total number of residents in the community regardless of hazard zone (based on 2010 census population counts) indicates a strong relationship $\left(r^{2}=0.91\right.$, where $r^{2}$ is the coefficient of determination and 1.0 indicates a perfect fit between data and a statistical model). If Whittier is removed from the comparison, the $r^{2}$ value increases to 0.999 , indicating that Whittier is the primary outlier. This suggests that the level of residential development in hazard zones is related to the size of the community, wherein smaller communities have lower 

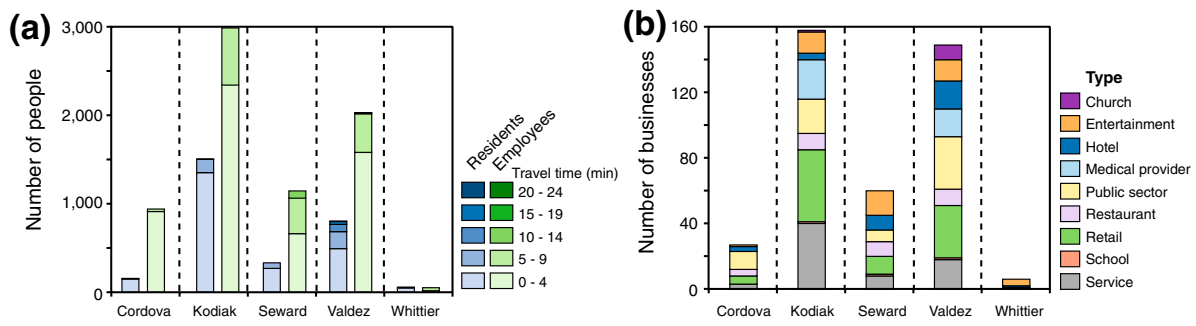

Fig. 2 Number of a residents and employees and $\mathbf{b}$ businesses in maximum tsunami hazard zones as a function of modeled pedestrian travel time to reach the boundary of a tsunami hazard zone, assuming a slow walking speed

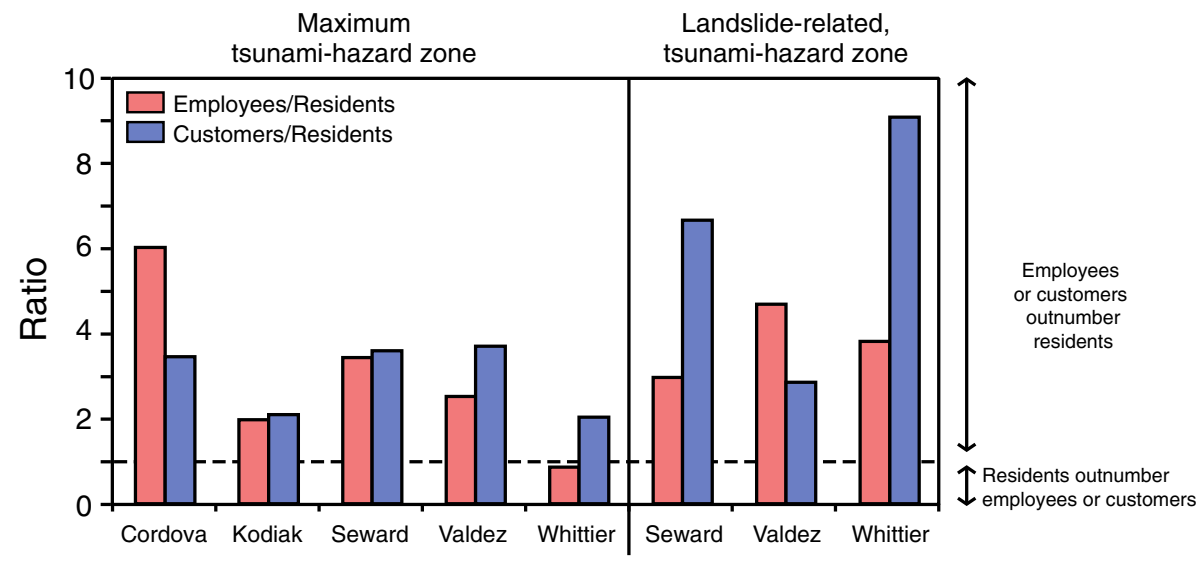

Fig. 3 Estimated ratios of employees to residents and customers to residents in Cordova, Kodiak, Seward, and Whittier, Alaska, based on employee populations and an assumption of 20 customers at certain types of businesses in maximum and landslide-related tsunami hazard zones

percentages of their population in hazard zones than the larger communities (e.g., Cordova has $7 \%$ of its 2,239 residents in the hazard zone, whereas Kodiak has $25 \%$ of its 6,130 residents in the hazard zone). The exception is Whittier where there is a much higher percentage of its residents in the tsunami hazard zone $(27 \%)$ than would be expected based on the size of the community (220 residents).

The number of employees in the tsunami hazard zone also has a strong relationship $\left(r^{2}=0.90\right)$ to the total workforce in a community. If Valdez is removed from the comparison, the $r^{2}$ value increases to 0.997 , indicating that Valdez has a disproportionate percentage of its employees in the hazard zone relative to the other communities. For example, Seward and Valdez have similar numbers of total employees (2,712 and 2,737, respectively); however, the percentage of employees in the hazard zone is much lower in Seward $(42 \%)$ than in Valdez $(74 \%)$.

Across all five communities, pedestrian evacuation times (assuming a slow walking speed) range from 1 to 48 min to reach a boundary of the maximum tsunami hazard zones (Fig. 1). Travel times out of hazard zones are $<20 \mathrm{~min}$ in populated areas of Cordova, Kodiak, Whittier, and Seward and are greater in natural areas where human occupation is unlikely (e.g., isolated wetlands far from development). Travel times out of hazard zones 
for much of Valdez are similar (i.e., $<20$ min), except for Ammunition Island (Fig. 1), development due east of Ammunition Island, and the entrance of Lowe River southeast of Valdez. Travel times to high ground are estimated to be as high as $45 \mathrm{~min}$ from the southern shore of Ammunition Island and $35 \mathrm{~min}$ from the mouth of Lowe River.

The majority of residents and employees in the maximum tsunami hazard zones of all five communities would likely require $10 \mathrm{~min}$ or less to reach high ground (Fig. 2a). Although there are some segments of the Valdez landscape where travel times are higher, residents and employees are estimated to be at locations that would require $<22 \mathrm{~min}$ to reach a boundary of the tsunami hazard zone (85\% of residents and $99 \%$ of employees requiring $<10 \mathrm{~min})$. Therefore, estimated travel times out of tsunami hazard zones (assuming a slow walking speed and for the considered scenarios) may be less than the predicted wave arrival times in all of the five communities (Table 1). Individuals on Ammunition Island in Valdez may have sufficient time to reach high ground as well, given estimated pedestrian travel times to reach a boundary of the tsunami hazard zone and wave arrival time are both approximately $45 \mathrm{~min}$.

In addition to residents and employees, the maximum tsunami hazard zones collectively contain 400 public venues, dependent-care businesses or businesses and organizations that otherwise attract significant numbers of customers (Fig. 2b). The distribution of these types of businesses in the hazard zones is similar to that of residents and employees in that most are in Kodiak (40\%) and Valdez (37\%). Retail businesses, restaurants, hotels, public sector offices (e.g., city government), and service providers (e.g., law offices, realties, beauty salon) are the most common business types in the maximum tsunami hazard zone. For discussion purposes only, we assume that locations we identified as public venues, dependent-care populations, and community businesses/agencies could have at least 20 visitors/customers on site during business hours. This assumption is reasonable for some businesses (e.g., restaurant, retail, or city office) and underestimates customers at other businesses or organizations (e.g., hotel or church). Even with this low population assumption, the ratio of customers to residents in the maximum tsunami hazard zones ranges from 2:1 (Whittier and Kodiak) to 4:1 (Valdez and Seward) (Fig. 3).

In all communities, businesses and offices that likely attract substantial customers are in locations that, according to our estimates, would require $<7 \mathrm{~min}$ for evacuees to reach high ground (Fig. 1). Therefore, employees and customers at these businesses would have enough time to reach a boundary of the tsunami hazard zone before tectonic-related wave arrival (30-60 min, depending on community), providing they recognize natural cues of imminent waves (e.g., ground shaking), are attentive to any formal warning notification, and don't delay in evacuating. This estimate ignores time required to leave buildings; therefore, follow-up research may be warranted for buildings with high population counts and limited egress options.

\subsection{Population exposure to landslide tsunamis}

Although results indicate that there may be sufficient time for individuals to reach high ground before tectonically generated tsunami waves arrive, the same cannot be said for landslide-related tsunami hazard zones. Modeling results suggest that there are large portions of the communities with estimated travel times out of hazard zones (based on a slow walking speed of $1.1 \mathrm{~m} / \mathrm{s}$ ) greater than scenario wave arrival times ( $1 \mathrm{~min}$ in Seward and Whittier and 2 min for Valdez) (Fig. 4). The areas where evacuations may be difficult, given the distance and small amount of time before wave arrival, are at the ends of docks in 


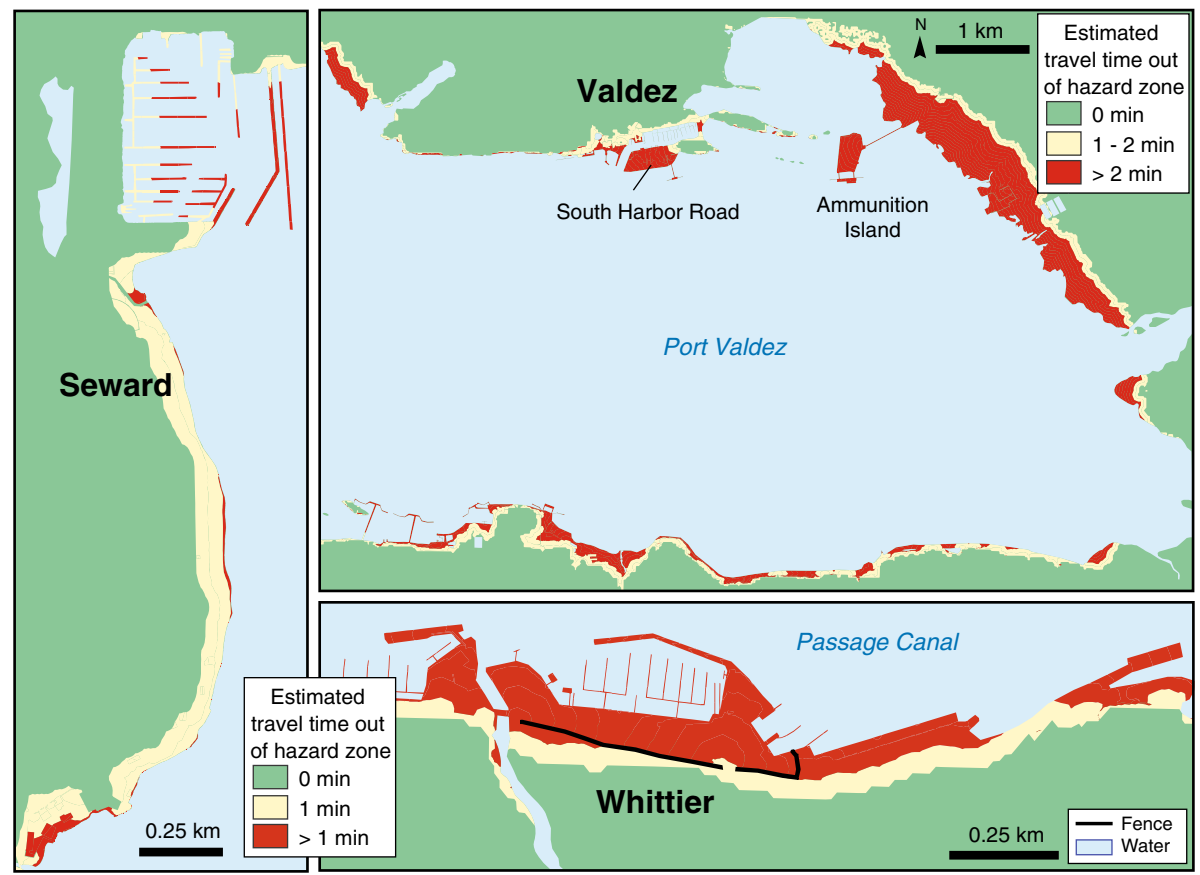

Fig. 4 Maps of modeled pedestrian evacuation travel times to reach the boundary of tsunami hazard zones in Seward, Valdez, and Whittier (Alaska, USA) relative to landslide-related tsunami hazard zones and assuming a slow walking speed of $1.1 \mathrm{~m} / \mathrm{s}$. Map extents for each community vary considerably and are based on the extent of resident and employee locations within the hazard zone of a community. Colors for travel times are based on estimated wave arrival times, which is different in Valdez (2 min) from Seward and Whittier (1 min)

Seward, the majority of the Whittier waterfront, and multiple areas in Valdez (e.g., South Harbor Road, Ammunition Island, and the mainland near Ammunition Island).

The landslide-related tsunami hazard zones in Seward, Valdez, and Whittier contain 130 residents, 543 employees, and 29 businesses or offices that likely attract significant numbers of customers (Fig. 5). The majority of the residents (64\%) and employees (73\%) in landslide-related tsunami hazard zones are in Valdez. Most businesses with significant customer bases are in Seward or Valdez (both $41 \%$ of the total employees) and are largely tourism-related businesses (e.g., charter boats, hotels, and retail). The ratio of employees to residents in landslide-related tsunami hazard zones ranges from 3:1 in Seward to 5:1 in Valdez (Fig. 3). If we assume locations we identified earlier as public venues, dependentcare populations, and community businesses/agencies could have at least 20 visitors/customers on site during business hours, the ratio of customers at businesses to residents in their homes in the hazard zone ranges from 3:1 in Valdez to 9:1 in Whittier (Fig. 3).

Although the number of residents, employees, and businesses in landslide-related tsunami hazard zones is substantially less than in the maximum tsunami hazard zones discussed earlier, the potential for life loss is greater for landslide-related tsunamis if one factors in evacuation travel times out of hazard zones (Fig. 5). The numbers of residents and employees in areas where there may be insufficient time to evacuate are similar in Seward (16 residents, 89 employees) and Whittier (11 residents, 42 employees). In Valdez, 


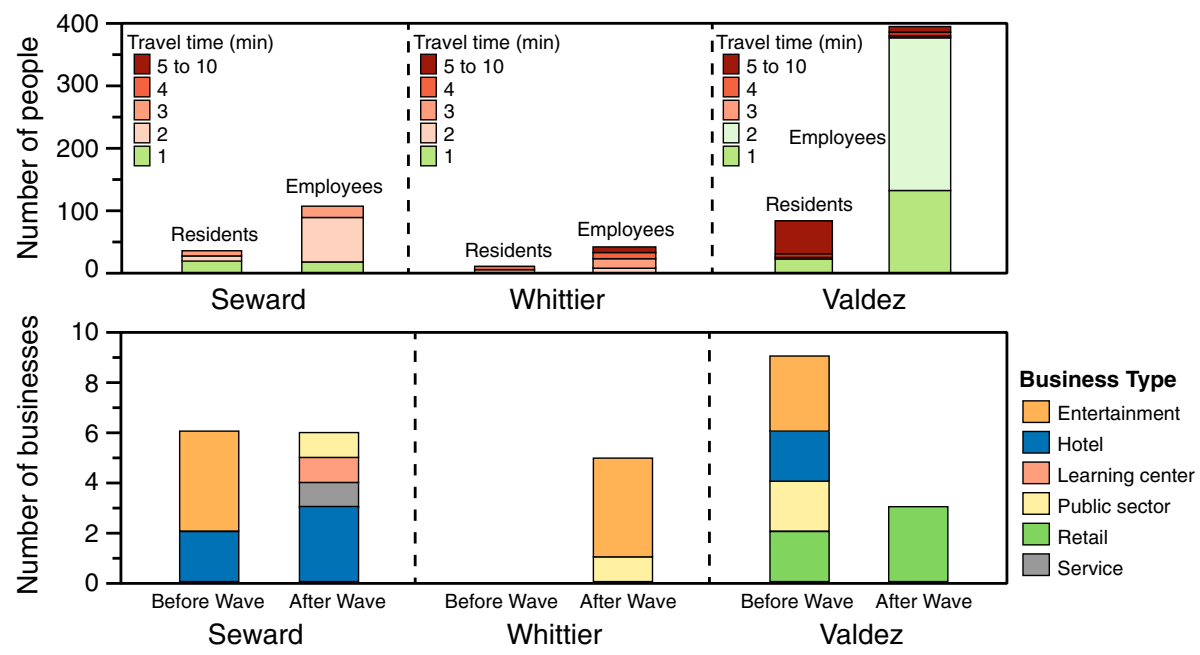

Fig. 5 Number of residents and employees in landslide-generated tsunami hazard zones as a function of modeled pedestrian travel time to reach the boundary of a tsunami hazard zone, assuming a slow walking speed

the number of employees is lower (18), but the number of residents is higher (61). Most, but not all, of the businesses or offices with significant customer bases are located in areas where evacuation travel times to the boundary of a tsunami hazard zone are $<1 \mathrm{~min}$, suggesting that there is sufficient time. Exceptions to this where at-risk individuals may have insufficient time to evacuate is a market and two car-rental services in Valdez, several tourism operators along the waterfront and the harbor master in Whittier, a U.S. Coast Guard vessel in Seward (which may or may not be in port when a tsunami occurs), three hotels in Seward, and a university learning center in Seward (Fig. 5).

\subsection{Docks and waterfronts as population hotspots}

Although an analysis of population exposure using established census and economic data yields considerable insight into potential vulnerabilities, it does not provide a complete assessment due to the high number of tourists and seasonal workers that come to Alaskan coastal communities for employment in the fishing industry, specific celebrations, or general tourism, especially during summer months between May and September. For example, the town of Seward (2010 residential population of 2,693) welcomes approximately 20,000 people to its annual Mt. Marathon run on 4th of July weekend (Erin Lemas, City of Seward, personal communication, April 21, 2014), representing a $743 \%$ increase in the number of people that may be near the waterfront (e.g., sightseeing before or after the race) in the event of a tsunami.

Seasonal fishing crew members and processing plant employees associated with the various fishing seasons are additional population groups that could also be overlooked in official population counts and are concentrated in waterfront areas. For example, commercial sockeye salmon seasons run from May to September and can add a minimum of 2,000 people working along the waterfront in Cordova (Christa Hoover, Cordova Chamber of Commerce, personal communication, April 21, 2014). During peak summer months, the 
State of Alaska estimates that over 31,000 people can find work in Alaskan coastal communities on fishing vessels or in processing plants related to the commercial salmon fisheries (AlaskaJobFinder 2014).

Another group of individuals likely to be in tsunami hazard zones are tourists brought in weekly by cruise ships for several hours during a port of call, especially during summer months between May and September. Various cruise ships that can accommodate 2,000-3,000 passengers include Seward, Kodiak, Whittier, and Valdez as ports of call or as departure and arrival ports (Alaska Tour and Travel 2014). For example, one cruise ship that can accommodate over 3,000 guests embarks and disembarks passengers from Whittier on the same day (Alaska Tour and Travel 2014), meaning there could be 6,000 people (i.e., 3,000 tourists finishing a cruise and another 3,000 tourists starting a new cruise) along the waterfront. This represents a 1,363\% increase in possible at-risk individuals over the normal residential population of 220 in Whittier (2010 U.S. Census Bureau count) that may be at risk if a tsunami were to occur.

Each of these examples of tourist and employee populations represent a potential influx of people who may have less awareness of tsunami threats and of how to evacuate to higher ground. In addition, close-up maps of docks in each of our case study communities suggest that these areas not only have high tourist flows but also have the highest travel times to reach a boundary of the tsunami hazard zone in each of the communities (Fig. 6). In all of our communities, at-risk individuals on the mainland do not have very far to go to reach high ground and can likely reach it before estimated wave arrival. However, people caught on docks during a landslide-related tsunami may have insufficient time to get out of estimated hazard zones. For our three landslide-related tsunami scenarios (Fig. 6a-c), waves would likely arrive ( $1 \mathrm{~min}$ in Seward and Whittier and 2 min in Valdez) before people would be able to evacuate (up to $10 \mathrm{~min}$ on certain dock sections in each community). In Cordova and Kodiak (Fig. 6d, e), people on docks will have less of an evacuation challenge than the other towns given the later wave arrivals from tectonically generated tsunamis (60 $\mathrm{min}$ ); however, the larger issue that highest evacuation times are on the docks still remains.

\section{Discussion}

Understanding how individuals in coastal communities are vulnerable to tsunamis is a critical step in understanding how to educate them on proper and efficient response to future events. Previous efforts have framed population vulnerability to tsunamis by looking at one credible source (typically a worst-case scenario) or at composite zones that combine all sources to produce a maximum area of potential inundation. These assumptions may be appropriate for guiding general tsunami outreach that strives to engage community members and raise tsunami awareness, but may not be sufficient for providing actionable information for specific threats. In this section, we discuss the implications of our results on risk reduction planning in Alaska and on population vulnerability studies as they relate to tsunami hazards in general throughout the world.

\subsection{Implications for risk reduction efforts}

Results suggest that the thousands of at-risk residents, employees, and customers in our five case study communities may have sufficient time to leave modeled tsunami hazard zones that are generated by tectonic activity (Figs. 1,2). This, however, assumes that at- 


\section{Landslide tsunami sources}

(a) Seward (wave arrival = $1 \mathrm{~min}$ )

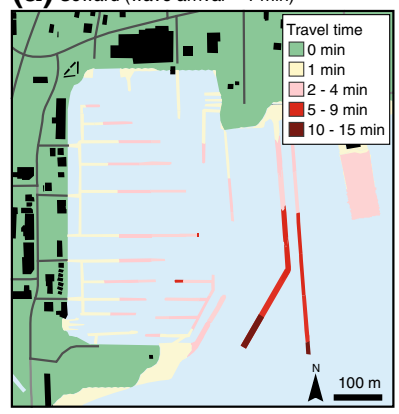

Tectonic tsunami sources

(d) Cordova (wave arrival = $60 \mathrm{~min}$ )

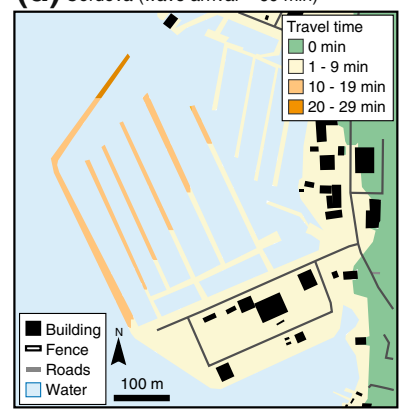

(b) Whittier (wave arrival = $1 \mathrm{~min}$ )

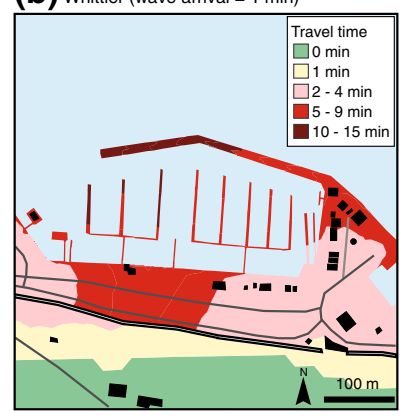

(C) Valdez (wave arrival = $2 \mathrm{~min}$ )

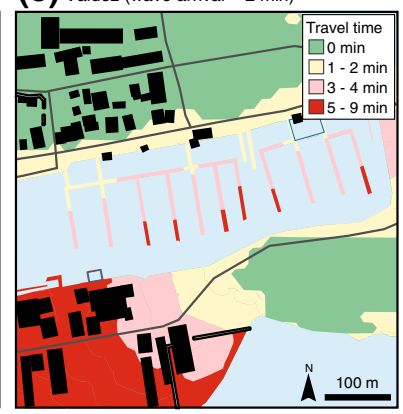

(e) Kodiak (wave arrival = $60 \mathrm{~min}$ )

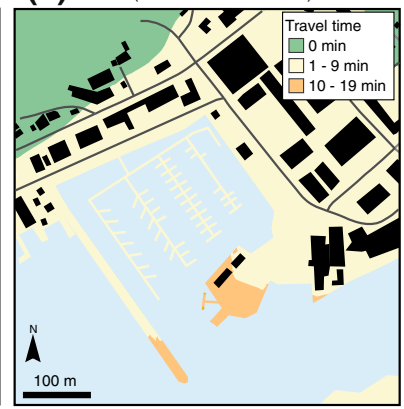

Fig. 6 Maps of modeled pedestrian evacuation travel times along the waterfront and on the docks of the case study communities, assuming a slow walking speed of $1.1 \mathrm{~m} / \mathrm{s}$ and landslide-related tsunami hazard zones in a Seward, b Whittier, and c Valdez, Alaska and maximum tsunami hazard zones in d Cordova and e Kodiak, Alaska

risk individuals recognize natural cues, understand that they are in areas prone to inundation, decide quickly to initiate movement toward safety, know where to go, and have the capacity to move. All of this suggests that effective risk reduction efforts to minimize loss of life from tectonically generated waves in these communities may wish to focus on education and training related to tsunami awareness, recognition of natural cues, and evacuation procedures. Although results are promising, they should not be interpreted as suggesting that no life loss or injury is possible from tectonically generated tsunamis in our case study communities. Future tsunamis may have different characteristics than the modeled scenarios, and there is the possibility of smaller waves that arrive sooner than expected and inundate portions of the hazard zone.

For landslide-related tsunamis, education and evacuation training may be an effective risk reduction strategy for some, but not all, at-risk populations in these smaller hazard zones. In Valdez, $83 \%$ of approximately 84 residents and 394 employees in landsliderelated tsunami hazard zones may only need 1-2 min to reach a boundary of the tsunami hazard zone but waves are expected to arrive 2 min after generation. In Seward, $26 \%$ of approximately 107 employees and 36 residents are in a similar situation (Fig. 5). Therefore, in both communities, well-placed signage and preparing these individuals for quick decision making and action through sustained tsunami education and evacuation training programs could save lives. However, not all at-risk individuals may have sufficient time to 
reach a boundary of the tsunami hazard zone (Figs. 4, 5). The issue of people on docks in Seward, Valdez, and Whittier not having enough time to evacuate was raised earlier (Fig. 6). Other areas where evacuations from landslide-related waves may not be successful are the Whittier waterfront (largely due to the obstacles presented by a fence running east-west), Ammunition Island in Valdez, and the western extent of South Harbor Road in Valdez (Fig. 4). Our results suggesting insufficient evacuation time for landsliderelated tsunamis are also supported by observations of the 1964 disaster, where the majority of tsunami-related deaths were along the waterfront and on docks and were associated with landslide-related waves (Lemke 1967).

While education and evacuation training still have significant roles to play in helping to prepare at-risk populations, other risk reduction strategies may warrant consideration. Strategic placement of vertical evacuation structures, tall buildings or mounds built in expected flooded areas, can offer safe refuge from tsunami inundation. Added signage indicating the direction people should travel and the amount of time they have to get out of a hazard zone could further improve individual's ability to understand what to do during a tsunami event. Other efforts could include educational information on cruise ships and the development of direct pathways to high ground from waterfront areas.

Emergency educators should note that immediate evacuations to avoid landslide-generated waves could conflict with common earthquake education and preparedness training. An encouraged reaction to an earthquake is to "drop, cover and hold" under sturdy furniture to avoid falling debris (e.g., ceiling panels, bookshelves). Eyewitness accounts of the 1964 disaster and modeling results, however, suggest landslide-related waves can arrive during the 3-4 min of initial ground shaking associated with a large earthquake. Therefore, if people in areas prone to landslide-related tsunami inundation decide to drop, cover, and hold during the earthquake, then they will have no time to evacuate. Additional discussion is warranted among hazard educators and at-risk individuals to determine when it may be advisable to immediately evacuate, instead of waiting for ground shaking to stop.

\subsection{Implications for population vulnerability studies}

Many population vulnerability studies focus primarily on residents by using population counts from national census agencies or global population estimates (e.g., Lovholt et al. 2012), likely due to the easy availability of data, consistency in acquisition, and ability to conduct longitudinal studies for tracking changes over time. Although this provides some insight into at-risk population dynamics, our results indicate that people in their homes represent the minority of people that may be in tsunami hazard zones (Fig. 3). In our five case study communities, employees at their workplace and customers in stores (which likely include residents that also live in a hazard zone) consistently outnumber residents at their homes in the maximum and landslide-related tsunami hazard zones (Fig. 3). Results suggest that although using census counts for residents at their homes may be easy because of data availability, it may drastically underestimate the number of people that may be in tsunami hazard zones.

A related topic that warrants additional research is gauging variations in the perceptions and preparedness of residents versus tourists. Past efforts to gauge tsunami hazard awareness, perceptions, and preparedness have largely focused on residents or public officials with responsibilities tied to public safety in hazard zones (e.g., Wood and Good 2005). Our results indicate that employees and customers at businesses or organizations far outnumber residents in the various tsunami hazard zones. Therefore, understanding how these at-risk populations may react to future tsunamis is important. This is more of an issue 
for landslide-related tsunamis, where hundreds of at-risk individuals in hazard zones may have enough time to evacuate prior to wave inundation (Fig. 5). For example, in Valdez, approximately 400 employees and 200 customers are in areas that may require $<2$ min to evacuate areas where landslide-related tsunami waves are estimated to arrive 2 min after generation (Fig. 5). This is less of an issue with the tectonic tsunami hazard zone, given that estimated travel times to reach a boundary of the tsunami hazard zone (maximum of 22 min in Valdez) are substantially less than wave arrival times (from 30 min in Seward up to $60 \mathrm{~min}$ in Cordova). Employees and customers may not be as aware of what to do, but would hopefully imitate the behavior of residents that evacuate from the tectonically generated waves.

Results from this study also highlight potential issues with evacuation modeling efforts that focus exclusively on where population has been assigned. For example, agent-based modeling simulates the movement of the at-risk individual as an agent instead of focusing on the evacuation landscape as we do in this study. Although agent-based modeling and other microsimulation efforts are incredibly useful in providing insight on evacuation behavior and potential congestion areas, they do not account for areas where at-risk individuals may be at some point during the day, unless population is assigned specifically to a location for a specific scenario. One such area prone to highly dynamic population magnitudes are docks and waterfronts in our five coastal communities (Fig. 6), where we reported earlier that these areas can attract thousands of tourists, because of either special events or those related to cruise ships. This suggests the need to recognize the potential for high-occupancy areas in communities in future microsimulation efforts, possibly as specific scenarios (e.g., tourist season in general or an annual festival), instead of only focusing on agent locations based on existing population data.

Another issue raised by this study is the practice of relying solely on maximum tsunami hazard zones to characterize and communicate societal vulnerability. As mentioned earlier, previous efforts to describe societal vulnerability to tsunami hazards have largely focused on using single events that typically represent a worst-case scenario or a composite that combines all plausible scenarios at a given site. Wave arrival times may be known and discussed, but not integral to an exposure analysis, which simply focuses on inventorying the number and type of at-risk individuals in the predicted tsunami hazard zone. In our case study communities, such an approach would lead one to conclude that Kodiak has the most significant tsunami issues, since it has almost 3,000 employees and 1,500 residents (not mutually exclusive populations) in the maximum tsunami hazard zone. However, wave arrival time is approximately $60 \mathrm{~min}$ after generation and our results suggest at-risk individuals are all within 10 min or less of high ground, based on a very conservative slow walking speed of $1.1 \mathrm{~m} / \mathrm{s}$. The city of Valdez has high numbers of at-risk individuals as well, but again, modeled travel times to reach a boundary of the tsunami hazard zone are on the order of $25 \mathrm{~min}$ or less for the maximum tsunami hazard zone, with wave arrival times of $45 \mathrm{~min}$ for a comparable tectonic tsunami.

An alternative way to look at population vulnerability is to focus on the ability of the atrisk population to evacuate out of the hazard zone and not simply on the number of people in the hazard zone. To do this, one can compare the number of people in a tsunami hazard zone for a specific scenario to the number of people that may not have enough time to evacuate before wave arrival (Fig. 7). In our case study communities, this comparison demonstrates that although the maximum tsunami hazard zones in Kodiak and Valdez contain the highest number of people (squares in Fig. 7), it is the substantially smaller hazard zones related to landslide scenarios in Valdez, Whittier, and Seward that pose the greatest threats to human life from a tsunami (circles in Fig. 7). In these communities and 
Fig. 7 Estimated total number of residents or employees in maximum or landslide-related tsunami hazard zones compared to the number of residents or employees in these zones in places where modeled travel time to reach the boundary of the hazard zone is greater than predicted wave arrival time. Arrival times are based on the considered scenarios and on modeling assumptions; however, future tsunamis may exhibit different characteristics and smaller waves may arrive sooner than modeled

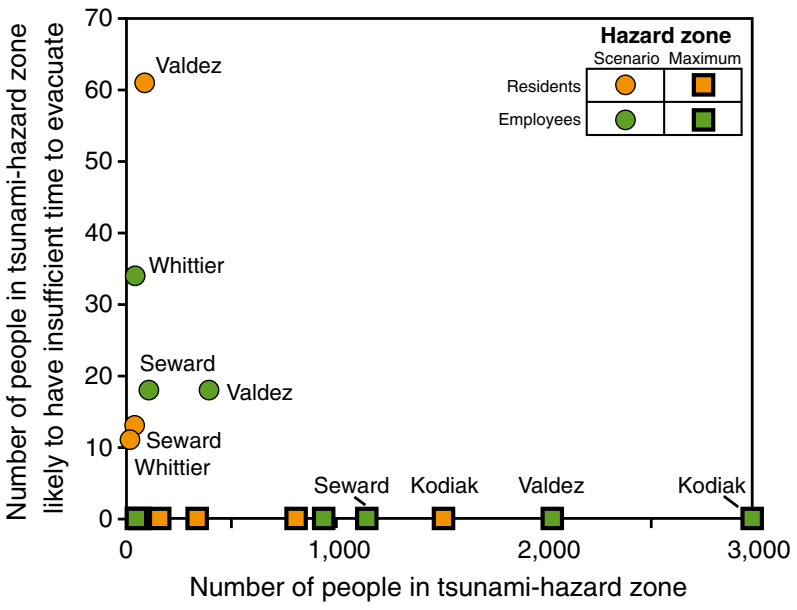

with these landslide scenarios, modeled results suggest there are people that could have insufficient time to evacuate before wave arrival.

Therefore, while the landslide-related tsunami hazard zones may be smaller in size compared to the tectonic scenarios and contain fewer at-risk people, they pose a larger threat to life because of shorter wave arrival times (1-2 min compared to 30-60 min). This conclusion that wave arrival time is an integral part of societal vulnerability to tsunami hazards has implications for local outreach; for example, the potential error results from treating all at-risk populations in a community the same way regardless of tsunami source. To alleviate this issue, communities may decide to make tsunami evacuation maps that recognize the different tsunami threats in a community, both in terms of hazard delineation and time available for successful evacuations. This finding also has implications for stateand national-level assessments and prioritizing resources that may emphasize communities with more people in the maximum hazard zone instead of taking into account the relationship between travel time out of hazard zones and predicted wave arrival times.

\section{Conclusions}

The goal of this paper was to examine how population vulnerability to tsunamis varies relative to multiple tsunami sources and subpopulations in hazard zones. Our analysis will help public officials to better gauge population vulnerabilities in their coastal communities and to target tsunami awareness and preparedness training. Based on our case study of community vulnerability to various tsunami threats in five Alaskan coastal communities, we reach several conclusions that bear on future tsunami risk reduction research and applications in other at-risk communities.

- The number of employees and customers are consistently greater than the number of residents in tectonic and landslide-related tsunami hazard zones, indicating the importance of tsunami education in the workplace and at high-occupancy tourist sites.

- Travel times to reach the boundary of hazard zones associated with tectonic sources are substantially less than estimated wave arrival times; therefore, casualties and injuries could be minimized with effective tsunami awareness and evacuation training. 
- Travel times to reach the boundary of hazard zones associated with submarine landslide sources are greater than estimated wave arrival times for many, but not all, at-risk populations, indicating the potential for life loss.

- Travel times out of hazard zones were typically highest on docks and along waterfront areas, which is consistent with historical records of life loss during the 1964 tsunami disaster.

- The potential for substantial visitor populations on docks and waterfront walkways warrant their inclusion in population vulnerability assessments, even if geospatial data are unavailable to model magnitudes.

- The common earthquake-preparedness training of "drop, cover, and hold" during an earthquake may not be advisable for individuals in areas prone to landslide-related tsunami inundation, given that waves may arrive before ground shaking stops.

These conclusions support the notion that population exposure assessments related to tsunami hazards must recognize non-residential populations and appreciate differences in the wave arrival times for various tsunami threats to a community. Vulnerability assessments and risk reduction efforts based purely on simple inventories of residential populations in maximum tsunami hazard zones will likely underestimate the societal threat that tsunamis pose. Failure to distinguish population exposures based on differences in wave arrival times may also focus attention on communities with significant at-risk populations but low life-safety issues because of the available time to evacuate; instead of on smaller at-risk populations in smaller hazard zones that may lack the ability to reach high ground. To fully appreciate the threat that tsunamis pose to coastal communities, managers and the at-risk population in these communities need to understand the evacuation context for various tsunami threats. This information not only helps local managers to develop targeted and realistic education and evacuation efforts in the threatened community, but also helps national policymakers in their efforts to efficiently allocate limited risk reduction resources.

Acknowledgments This study was supported by the US Geological Survey (USGS) Land Change Science Program. We thank Dmitry Nicolsky, Elena Suleimani, and Amy Macpherson of the Geophysical Institute at the University of Alaska Fairbanks for providing geospatial, tsunami hazard data of the five communities and for their guidance in interpreting hazard zones. We thank Mara Tongue of the USGS, Dmitry Nicolsky, and two anonymous reviewers for their insightful reviews of earlier versions of the article. Any use of trade, product, or firm names is for descriptive purposes only and does not imply endorsement by the US Government.

Open Access This article is distributed under the terms of the Creative Commons Attribution License which permits any use, distribution, and reproduction in any medium, provided the original author(s) and the source are credited.

\section{References}

Alaska Mapped (2013) Alaska Statewide Orthoimagery Mosaic. http://www.alaskamapped.org/ortho/. Accessed 20 Aug 2013

Alaska Tour and Travel (2014) 2014 Alaska cruise schedule. http://www.alaskatravel.com/alaska-cruises/ cruise-schedule.html. Accessed 47 April 2014

AlaskaJobFinder (2014) Alaska's commercial salmon fisheries jobs. http://www.alaskajobfinder.com/ jobseekers/salmon-fisheries.php

Arno N, McKinney L (1973) Harbor and waterfront facilities. In: Committee on the Alaska Earthquake of the National Research Council (ed) The great Alaska earthquake of 1964-engineering. National Academy of Sciences, Washington, DC, pp 526-643 
Barry M (1995) Seward, Alaska-a history of the gateway city. Volume 3 growth, tragedy, recovery, adaptation, 1924-1993. MJP Barry, Anchorage, Alaska

Bing Maps (2014) Cordova, Alaska. http://www.bing.com/maps. Accessed 20 Feb 2014

Coulter H, Migliaccio R (1966) Effects of the earthquake of March 27, 1964 at Valdez, Alaska. U.S. Geological Survey Professional Paper 542-C. United States Government Printing Office, Washington, $\mathrm{DC}$

Freire S, Aubrecht C, Wegscheider S (2013) Advancing tsunami risk assessment by improving spatiotemporal population exposure and evacuation modeling. Nat Hazards 68:1311-1324

Google Earth (2013) Whittier, Alaska. http://www.google.com/earth/. Accessed 20 Sept 2013

Grantz A, Plafker G, Kachadoorian R (1964) Alaska's Good Friday Earthquake, March 27, 1964, a preliminary geologic evaluation, Geological Survey Circular 491, United States Government Printing Office, Washington, DC

Hansen W, Eckel E, Schaem W, Lyle R, George W, Chance G (1966) The Alaska Earthquake March 27, 1964-field investigations and reconstruction effort, U.S. Geological Survey Professional Paper 541. United States Government Printing Office, Washington, DC

Hubbard T, Wolken G, Stevens D, Combellick R (2013) High-resolution lidar data for the Whittier area, Passage Canal, and Portage Lake, Alaska, in DGGS Staff, LiDAR Datasets of Alaska. Alaska Division of Geological \& Geophysical Surveys Raw Data File 2013-3, 5 p. doi: 10.14509/24976

Infogroup (2011) Employer database. http://www.infousagov.com/employer.asp. Accessed 1 Oct 2011

Jonkmann S, Vrijling J, Vrouwenvelder A (2008) Methods for the estimation of loss of life due to floods: a literature review and a proposal for a new method. Nat Hazards 46:353-389

Kenai Peninsula Borough GIS Division (2013) Geographic information systems downloads. http://www2. borough.kenai.ak.us/GISDept/Downloads.html. Accessed 7 Jan 2013

Lander J (1996) Tsunamis affecting Alaska 1737-1996. NCGC Key to Geophysical Research Documentation No 31. National Geophysical Data Center, Boulder, CO

Lemke R (1967) Effects of the earthquake of March 27, 1964, at Seward, Alaska. Geological Survey Professional Paper 542-E. United States Government Printing Office, Washington, DC

Lovholt F, Glimsdal S, Harbitz C, Zamora N, Nadim F, Peduzzi P, Dao H, Smebye H (2012) Tsunami hazard and exposure on the global scale. Earth Sci Rev 110(1-4):58-73

National Geophysical Data Center/World Data Service (2014) Global Historical Tsunami Database. http:// www.ngdc.noaa.gov/hazard/tsu_db.shtml. Accessed 28 Jan 2014

National Research Council (2011) Tsunami warning and preparedness: an assessment of the US Tsunami Program and the Nation's preparedness efforts, Committee on the review of the tsunami warning and forecast system and overview of the nation's tsunami preparedness. The National Academies Press, Washington, DC

Nicolsky D, Suleimani E, Combellick R, Hansen R (2011) Tsunami inundation maps of Whittier and western Passage Canal, Alaska. Alaska Division of Geological \& Geophysical Surveys Report of Investigation 2011-7, $65 \mathrm{p}$

Nicolsky D, Suleimani E, Haeussler P, Ryan H, Koehler R, Combellick R, Hansen R (2013) Tsunami inundation maps of Port Valdez, Alaska. Alaska Division of Geological \& Geophysical Surveys Report of Investigation 2013-1, 77 p, 1 sheet, scale 1:12,500

Nicolsky D, Suleimani E, Koehler R (2014) Tsunami inundation maps of Cordova and Tatitlek, Alaska. Alaska Division of Geological \& Geophysical Surveys Report of Investigation 2014-1, 49 p

Norton F, Haas J (1970) The cities and towns-Anchorage, Kodiak, Whittier, Seward, Seldovia, Cordova, Valdez. In: Committee on the Alaska Earthquake of the National Research Council (ed) The great Alaska earthquake of 1964-human ecology. National Academy of Sciences, Washington, DC, pp 248-356

Oregon Department of Geology and Mineral Industries (2013) Tsunami inundation and evacuation maps for Oregon, Fact Sheet. http://www.oregongeology.org/pubs/fs/TIM-maps-factsheet.pdf. Accessed 12 May 2014

Park S, van de Lindt J, Gupta R, Cox D (2012) Method to determine the locations of tsunami vertical evacuation shelters. Nat Hazard 63:891-908

Post J, Wegscheider S, Muck M, Zosseder K, Kiefl R, Steinmetz T, Strunz G (2009) Assessment of human immediate response capability related to tsunami threats in Indonesia at a sub-national scale. Nat Hazards Earth Syst Sci 9:1075-1086

Rogers G (1970) Economic effects of the earthquake. The great Alaska earthquake of 1964-human ecology. National Academy of Sciences, Washington, DC, pp 58-76

Soule R, Goldman R (1972) Terrain coefficients for energy cost prediction. J Appl Physiol 32:706-708 
Suleimani E, Hansen R, Combellick R, Carver G (2002) Tsunami hazard maps of the Kodiak area, Alaska. Alaska Division of Geological \& Geophysical Surveys Report of Investigation 2002-1, 16 p, 4 sheets, scale $1: 12,500$

Suleimani E, Nicolsky D, West D, Combellick R, Hansen R (2010) Tsunami inundation maps of Seward and northern Resurrection Bay, Alaska. Alaska Division of Geological \& Geophysical Surveys Report of Investigation 2010-1, 47 p, 3 sheets, scale 1:12,500

Tobler W (1993) Three presentations on geographical analysis and modeling-non-isotropic geographic modeling. Speculations on the geometry of geography; and global spatial analysis. UCSB. National Center for Geographic Information and Analysis Technical Report 93-1. http://www.ncgia.ucsb.edu/ Publications/Tech_Reports/93/93-1.PDF. Accessed 19 July 2010

United States Census Bureau (2012) American factfinder. http://factfinder2.census.gov/faces/nav/jsf/pages/ index.xhtml. Accessed 27 Oct 2012

United States Department of Transportation (2009) Manual on uniform traffic control devices for streets and highways. Federal Highway Administration

United States Geological Survey (2012) Earthquake “Top 10” Lists \& Maps. http://earthquake.usgs.gov/ earthquakes/eqarchives/. Accessed 26 Oct 2012

United States Geological Survey (2013) National Elevation Dataset. http://viewer.nationalmap.gov/viewer/. Accessed 1 Oct 2013

Walsh T, Caruthers C, Heinitz A, Myers III E, Baptista A, Erdakos G, Kamphaus R (2000) Tsunami hazard map of the southern Washington coast-modeled tsunami inundation from a Cascadia subduction zone earthquake. Washington Department of Natural Resources Division of Geology and Earth Resources Geologic Map GM-49

Wilson R, Barberopoulou A, Miller K, Goltz J, Synolakis C (2008) New maximum tsunami inundation maps for use by local emergency planners in the State of California, USA: EOS, Transactions of the American Geophysical Union, v. 89, no. 53, Fall Meeting Supplement, Abstract OS43D-1343

Wood N (2007) Variations in community exposure and sensitivity to tsunami hazards in Oregon. Reston, Va., USGS Scientific Investigations Report 2007-5283, 43 p

Wood N, Good J (2005) Perceptions of earthquake and tsunami issues in U.S. Pacific Northwest port and harbor communities. Int J Mass Emerg Disasters 23(3):103-138

Wood N, Schmidtlein M (2012) Anisotropic path modeling to assess pedestrian-evacuation potential from Cascadia-related tsunamis in the U.S. Pacific Northwest. Nat Hazards 62(2):275-300

Wood N, Schmidtlein M (2013) Community variations in population exposure to near-field tsunami hazards as a function of pedestrian travel time to safety. Nat Hazards 65(3):1603-1628

Wood N, Burton C, Cutter S (2010) Community variations in social vulnerability to Cascadia-related tsunamis in the U.S. Pacific Northwest. Nat Hazards 52(2):369-389

Wood N, Jones J, Schelling J, Schmidtlein M (2014) Tsunami vertical-evacuation planning in the U.S. Pacific Northwest as a geospatial, multi-criteria decision problem. Int J Disaster Risk Reduct 9:68-83

Yeh H, Fiez T, Karon J (2009) A comprehensive tsunami simulator for Long Beach Peninsula phase-1framework development final report. State of Washington Military Department Emergency Management Division 